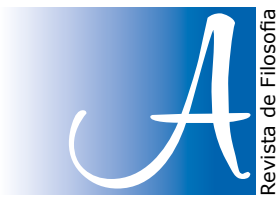

ARGUMENTOS

\title{
O valor da ciência e a busca pela verdade, bem e belo na filosofia de Henri Poincaré
}

The value of science and the search for truth, goodness and beauty in the philosophy of Henri Poincaré

\section{RESUMO}

A questão do valor da ciência sempre foi de suma importância para filósofos e cientistas. Poderemos reduzir a ciência a seus resultados utilitários ou a pesquisa científica possui algum valor intelectual intrínseco, independente de sua dimensão prática? Neste artigo abordamos a questão tendo como fio condutor o pensamento do matemático filósofo convencionalista Henri Poincaré. Veremos como Poincaré concebe o valor da ciência e defende a busca da verdade e o cultivo da beleza e do bem moral como núcleos de sua visão de ciência pela ciência.

Palavras-chave: Valor da ciência. Ordem e unidade. Utilitarismo.

\section{ABSTRACT}

The question of the value of science has always been of paramount importance to philosophers and scientists. Can we reduce science to its utilitarian results or does scientific research possess any intrinsic intellectual value, independent of its practical dimension? In this article we approach the question having as a guiding thread the thought of the mathematical conventionalist philosopher Henri Poincaré. We shall see how Poincaré conceives the value of science and defends the pursuit of truth and the cultivation of beauty and moral good as nuclei of his vision of science for its own sake.

Keywords: Value of science. Order and unity. Utilitarianism.

\section{Introdução}

Henri Poincaré (1854-1912) foi um matemático, físico e filósofo francês, cujas contribuições científicas foram importantes no desenvolvimento da física relati-

* Doutor e Mestre em Filosofia (IMS-UERJ). http://orcid.org/0000-0002-1061-2727 
vístical. Como filósofo defendeu uma perspectiva convencionalista segundo a qual as teorias físicas são convenções, isto é, modelos aceitos pela comunidade científica. Como tais, não são, ontologicamente, nem verdadeiros nem falsos. As teorias, enquanto representações ou modelos, não podem, e nem devem ser, explicações verdadeiras da realidade tal como ela é, mas "imagens" epistemologicamente úteis (ou fecundas), logicamente simples e empiricamente profícuas, capazes de nos oferecer quadros de compreensão da realidade física, ainda que provisórios e convencionais. Sendo assim, a verdade de uma teoria não decorre de sua adequação com a realidade, como defendem os realistas, mas da satisfação de critérios socialmente compartilhados pelos membros de uma comunidade de praticantes de ciência em uma área específica do conhecimento.

O convencionalismo não deve ser confundido com um relativismo subjetivista, que nivelaria teorias concorrentes ao mesmo grau de indeterminação epistemológica, reduzindo o problema da escolha à arbitrariedade das "questões de gosto". Embora uma teoria não possa ser considerada ontologicamente verdadeira, no sentido de nunca ser uma explicação última e absoluta do real, existiriam critérios coletivamente aceitos, como simplicidade e coerência lógica, a partir dos quais algumas teorias poderiam ser consideradas mais desejáveis, fecundas e razoáveis do que outras ${ }^{2}$. Nesta oportunidade nosso objetivo será menos epistemológico e mais axiológico. Desse modo, deixaremos a questão do convencionalismo em segundo plano para tratarmos especificamente do problema do valor da ciência.

O valor da ciência é uma das questões filosóficas centrais abordadas por Poincaré. Neste artigo veremos como o cientista filósofo coloca o problema, defendendo uma concepção epistêmica que se contrapõe radicalmente a uma perspectiva que poderíamos chamar de "utilitarista" (na medida em que enaltece o conhecimento científico como um meio de produção de utilidades práticas). Para tanto, lançaremos mão de outros autores, a fim de contextualizar como o mesmo problema foi compreendido por intelectuais de diversos campos.

\section{Qual é o valor da ciência?}

A astronomia é útil porque nos eleva acima de nós mesmos; é útil porque é grande; é útil porque é bela; é isso que se precisa dizer.

Henri Poincaré

Em O valor da ciência (POINCARÉ, 1995) o matemático e filósofo francês Henri Poincaré defende que apesar da importância das realizações práticas da ciência, o valor da pesquisa científica é intrínseco (POINCARÉ. 1995, p. 172). Esta é a ideia básica da noção de ciência pela ciência sustentada pelo autor:

\footnotetext{
${ }^{1}$ Acerca das relações científicas entre os trabalhos de Poincaré e Einstein, ver: PATY, M. A criação científica segundo Poincaré e Einstein. Estud. av., São Paulo, v. 15, n. 41, p. 157-192, Apr. 2001

${ }^{2}$ Para saber mais sobre o convencionalismo de Poincaré sugerimos: PAZ, M. O convencionalismo de Poincaré contextualizado. Kairós. Revista de Filosofia 7, p. 151-166, 2013. Centro de Filosofia das Ciências da Universidade de Lisboa.
} 
A busca da verdade deve ser o objetivo de nossa atividade: é o único fim digno dela. Não há dúvida de que devemos nos esforçar por aliviar os sofrimentos humanos, mas por quê? Não sofrer é um ideal negativo que seria atingido mais seguramente com o aniquilamento do mundo. Se cada vez mais queremos libertar o homem das preocupações materiais, é para que ele possa empregar no estudo e na contemplação da verdade sua liberdade reconquistada. [...] para buscar a verdade é preciso ser independente, inteiramente independente. Se, ao contrário, desejamos agir, se queremos ser fortes, precisamos estar unidos. Eis porque muitos de nós se amedrontam com a verdade; consideram-na uma causa de fraqueza. E contudo não se deve temê-la, porque só a verdade é bela. (POINCARÉ. 1995, p. 4-5).

Logo nas primeiras linhas de O valor da ciência (POINCARÉ, 1907), Poincaré atrela o sentido da investigação da natureza à busca pela verdade, o bem e o belo. Na citação acima, é fácil perceber como ele vincula a beleza, em sentido sublime, invulgar e intelectual, à verdade. Só a verdade é bela, sentencia. Mas vai além, pois ressalta que não devemos desvincular a busca da verdade da busca por justiça, paz e prosperidade. Tal vínculo fica ainda mais claro quando afirma que duas verdades devem ser reunidas: a verdade científica e a verdade moral. Embora comumente sejam pensadas como coisas estanques, Poincaré confessa:

[...] não posso separá-las, e aqueles que amam uma não podem deixar de amar a outra. Para encontrar uma, assim como para encontrar a outra, é preciso esforçar-se para se libertar completamente a alma do preconceito e da paixão, é preciso alcançar a sinceridade absoluta. Essas duas espécies de verdade, uma vez descobertas, irão proporcionar-nos a mesma alegria; tanto uma como a outra, assim que as percebemos, brilham com o mesmo esplendor, de tal modo que devemos vê-las ou fechar os olhos. Ambas, enfim, nos atraem e nos escapam; jamais estão fixas: quando cremos tê-las atingido, vemos que ainda é preciso caminhar, e aquele que as persegue está condenado a jamais conhecer o descanso. (POINCARÉ. 1995, p. 4-5); (POINCARÉ, 1907).

Para Poincaré, o homem de ciência deve possuir um ethos peculiar. Deve amar tanto a verdade científica quanto a verdade moral, mas, ao mesmo tempo, compreender que tais verdades jamais serão plenamente conquistadas, o que exige daquele que a busca imenso desapego, resignação e humildade, e uma atitude marcada pela determinação. Virtudes epistêmicas e morais, conhecimentos e valores, embora ciência e moral sejam campos independentes, são igualmente importantes para o investigador. Ele deve ser independente, desinteressado, sincero e determinado, deve lutar pela verdade e pela beleza, e agir conforme o bem e a justiça. Não é o lucro, o poder, o status, que deve movê-lo, nem a utilidade prática imediata que deve inspirá-lo, mas a verdade, que é bela, e o ideal de uma boa vida social comum, justa, sem sofrimentos. Claro que tal imagem de cientista nos pareceria caricatural se forjada hoje, no seio do século XXI, mas então não estaríamos sendo presentistas, julgando o passado demasiado cândido por que o avaliamos a partir da malícia do presente? O fato é que Poincaré, e tantos outros homens que dificilmente podem ser chamados de ingênuos ou estúpidos, fizeram questão de retratar desta forma o ethos que o investigador científico deveria cultivar. 


\section{Metafísica e axiologia}

Muitas pessoas acreditam - na sua ignorância completa do que é realmente a ciência - que sua tarefa prioritária é inventar nova maquinaria ou ajudar a inventá-la, de forma a melhorar as nossas condições de vida.

Erwin Schrödinger

Poincaré ilustra bem a relação entre metafísica e axiologia, ou entre pressupostos metafísicos e princípios axiológicos. Por que o homem de ciência deve ser um investigador determinado, tenaz, humilde, senão porque assume certos pressupostos acerca da realidade e do conhecimento? No espírito ${ }^{3}$, ou no mundo exterior, o princípio de ordem e unidade da natureza é um pressuposto metafísico do qual o investigador, segundo Poincaré e tantos outros, como Planck, Einstein, Heisenberg e Schrödinger (SILVA, 2017, p. 233-250), não pode prescindir. A ordem, ou harmonia, é expressão da lei, e a beleza, seu resultado. Não há nada que possa nos provocar maior sensação de embevecimento e espanto do que a harmonia da natureza:

A melhor expressão dessa harmonia é a lei. A lei é uma das mais recentes conquistas do espírito humano; ainda há povos que vivem num milagre perpétuo e que não se espantam com isso. Somos nós, ao contrário, que deveríamos nos espantar com a regularidade da natureza. Os homens pedem a seus deuses que provem sua existência com milagres; mas a maravilha eterna é o fato de não haver milagres a todo instante. E é por isso que o mundo é divino, já que é por isso que ele é harmonioso. Se fosse regido pelo capricho, o que nos provaria que não é regido pelo acaso? (POINCARÉ. 1995, p. 8).

Parece que a ideia de ordem e unidade da natureza não é assim tão recente como tal sentença de Poincaré nos está a dizer. Bastaria verificar que o que marca o início da cosmologia grega há 2500 anos é justamente a noção de que a natureza possui ordem e unidade. Mas vamos além e verificaremos que até mesmo a coexistência entre a busca da verdade e a utilidade prática ocorreu em outras culturas. Em Raça e História (LEVI-SRTAUSS, 1952), Lévi-Strauss lembra que os povos pré-colombianos desenvolveram arrojadas técnicas de manipulação e domesticação de venenos para uso farmacológico, diversas culturas vegetais, o que demandou avançados conhecimentos agronômicos, fizeram notáveis progressos em tecelagem, construção, metalurgia, mas também realizaram grandes avanços teóricos:

[...] finalmente o zero, base da aritmética e, indiretamente, das matemáticas modernas, era conhecido e utilizado pelos Maias pelo menos meio milênio antes da sua descoberta pelos sábios indianos, de quem a Europa o recebeu por intermédio dos Árabes. Talvez por esta mesma razão o seu calendário fosse mais exato que o do Velho Mundo. (LÉVISTRAUSS, 1952, p.22).

\footnotetext{
${ }^{3}$ Como convencionalista Poincaré não dirá, assim como o fará um realista, que a lei, a harmonia, sejam propriedades ontológicas do mundo externo, mas conquistas do espírito humano.
} 
Mesmo diante de tantos progressos dos pré-colombianos, ainda se pode objetar que os povos não ocidentais, mesmo no caso de suas realizações matemáticas, não possuíam a atitude da investigação desinteressada, da busca da verdade, e por isso não fizeram algo como "ciência". Os maias, por exemplo, utilizavam o zero mesmo antes dos indianos (tendo sido, portanto, o primeiro povo a fazê-lo de que se tem registro), mas o fizeram por demandas práticas, para organização do calendário e, portanto, da vida social e econômica, e não por que estavam interessados em matemática pura, nos números, na estrutura fundamental da natureza. Todavia, em O pensamento selvagem (LEVI-STRAUSS, 1989), Lévi-Strauss desconstrói a ideia de que o conhecimento entre as culturas não ocidentais sempre fora reduzido ao utilitarismo praticista. De acordo com Lévi-Strauss, em muitas culturas antigas, estranhas ao ocidente, houve conhecimento desinteressado. $O$ antropólogo cita diversos estudos acerca de tribos africanas, siberianas, nativas do território que hoje formam o Canadá e os Estados Unidos, dentre outras, que demonstram que seus sábios entendiam que a natureza deve ser conhecida, independente de quais utilidades práticas tal conhecimento será capaz de produzir. Acerca das investigações desinteressadas destes povos, Lévi-Strauss diz:

Pode-se objetar que tal ciência não deve absolutamente ser eficaz no plano prático. Mas, justamente, seu objeto primeiro não é de ordem prática. Ela antes corresponde a exigências intelectuais ao invés de satisfazer às necessidades. A verdadeira questão não é saber se o contato de um bico de picanço cura as dores de dente, mas se é possível, de um determinado ponto de vista, fazer "irem juntos" o bico do picanço e o dente do homem (congruência cuja fórmula terapêutica constitui apenas uma aplicação hipotética entre outras) [ou seja, verificar se há regularidades na natureza], e, através desses agrupamentos de coisas e de seres, introduzir um princípio de ordem no universo (sic) (LÉVI-STRAUSS. 1989, p. 24). [grifo nosso].

Temos de admitir, caso a tese de Lévi-Strauss esteja correta, que a busca desinteressada pela verdade, a 'necessidade' de compreender o mundo em termos de ordem e unidade, são características culturais muito mais amplas e multiétinicas do que geralmente supomos. Retornemos, todavia, ao pensamento de Poincaré e sua ideia de que a lei é uma conquista do espírito humano. $O$ valor da pesquisa científica, para o matemático filósofo, está, sendo assim, profundamente relacionado ao objeto da ciência e à motivação do cientista. $O$ objeto da ciência é o que há de mais sublime, logo a motivação do cientista não poderia ser menos nobre. Primeiro, devemos assumir que há uma harmonia. Eis a conquista do espírito em nossa interpretação. Posto que Poincaré não pense que tal harmonia está no mundo, mas no espírito que sonda suas estruturas e eventos, a grande conquista do espírito é compreender que, sem o pressuposto de ordenamento e unidade da natureza, isto é, sem pressupor a lei, não há ciência. Não pode haver ciência em um mundo em que não há regularidades, em que os fatos nunca se repetem, ou nunca se repetem de acordo com as mesmas causas, pois esse é o mundo mágico e fabuloso em que nada pode ser ordenado, previsto, classificado e controlado. A partir desse pressuposto, o investigador busca compreender ainda mais a harmonia que assumiu "estar lá", e à medida que aumenta sua compreensão da harmonia, se aproxima da verdade e se deleita com a beleza. 
[...] É portanto essa harmonia a única realidade objetiva, a única verdade que podemos atingir; e se acrescento que a harmonia universal do mundo é a fonte de toda beleza, será possível compreender o valor que atribuímos aos lentos e penosos progressos que nos fazem pouco a pouco, conhecê-la melhor. (POINCARÉ. 1995, p. 9).

Como já dissemos, tal harmonia não pode ser pensada como uma propriedade ontológica do mundo externo, mas como uma conquista do espírito. Sendo assim, poderíamos dizer que a harmonia não é objetiva, mas subjetiva. Entretanto, seria um equívoco de nossa parte. Do fato de que a harmonia não seja uma propriedade do mundo não se segue que não seja objetiva, pois sua objetividade pode ser devida a outras razões. Isto fica claro quando lemos como Videira trata da questão da harmonia no pensamento de Poincaré;

[...] é preciso que fique claro que essa mesma harmonia universal não pode ser conhecida fora do espírito humano. A rigor, ela é produto deste último. Essa mesma harmonia não é objetiva porque se refere a essência das coisas - a natureza em si não pode ser conhecida - , ela o é em função da sua característica de ser comum a todos os seres racionais. $\mathrm{E}$ posto que o comum não é fornecido imediatamente seja pelos sentidos, seja pela razão, mas é construído a partir do emprego destes, também a harmonia universal, para que se possa alcançá-la, exige que razão e sentidos interajam. (VIDEIRA. 1997, p. 8).

A objetividade da harmonia decorre de sua universalidade (é comum a todos os seres racionais). Ora, se é assim, se a harmonia não é pensada como uma propriedade intrínseca da natureza mesma, mas como algo do espírito, assim como a simplicidade é conquista evolutiva do espírito no movimento da adaptação ao real [Ibdem], que sentido há em afirmar que se trata de um pressuposto metafísico? Ocorre que neste trabalho não estamos tomando metafísica e ontologia por sinônimos, conforme Oliveira (2015) ${ }^{4}$. Estamos nos valendo tanto da definição de Blackburn (1997), de acordo com o qual a metafísica é um conjunto de pressupostos fundamentais, ou princípios básicos, acerca da natureza da realidade e do conhecimento, quanto da definição de Videira (2013), de metafísica como força de orientação. Por axiologia, ou sistema axiológico, compreendemos o conjunto de valores fundamentais de um determinado campo de trabalho, comunidade de praticantes de uma atividade específica, ou sociedade, em sentido mais geral. Pensamos que ao propor uma relação de compatibilidade e adequação entre pressupostos metafísicos e princípios axiológicos, podemos promover uma síntese entre ambas as definições, pois são os pressupostos assumidos, agregados aos princípios axiológicos que lhes são correlatos, que orientam a epistemologia e o ethos da pesquisa científica. Sendo assim, quando afirmamos que toda prática científica possui uma metafísica, não estamos dizendo outra coisa senão que

\footnotetext{
${ }^{4}$ Nesse sentido, acompanhamos Aercio Barbosa de Oliveira quando escreve em sua dissertação de mestrado: "Metafísica ao longo desta dissertação tem um significado diferente da interpretação tradicional que partiu das questões apresentadas por Aristóteles (384 a.C. - 322 a.C.). Aqui, metafisica é a designação de diferentes pressupostos aplicados a diferentes campos da ciência que não são possíveis serem confirmadas empiricamente, mas são essenciais para impulsionar a pesquisa científica (BOHM, 201 1, p. 109-1 15; BLACKBURN, 1997, p. 246)". OLIVEIRA, Aercio Barbosa. Originalidade e inovação na filosofia das ciências contemporânea: ainda faz sentido tratá-las como termos distintos? 2015. 158f. Dissertação (Mestrado em Filosofia) Instituto de Filosofia e Ciências Humanas, Universidade do Estado do Rio de Janeiro, Rio de Janeiro, 2015
} 
possui pressupostos; sejam estes realistas, idealistas ou convencionalistas, e, além disto, que possui um ethos compatível com os pressupostos assumidos.

Nenhum conhecimento, e quiçá nenhuma ação consciente racional, é isento de pressupostos. Alguns dos quais são tão tácitos, tão naturalizados, que nos esquecemos de sua história, do caminho que tiveram que percorrer até se tornarem fatos dados "óbvios", ou nem mesmo nunca nos damos conta de que são pressupostos. A todo momento, não podemos ter certeza, realmente, da veracidade de nossa experiência mais imediata, mas devemos seguir em frente e levar a vida, pressupondo que há um mundo do qual fazemos parte e que ele é tal e qual o experimentamos. Para Karl Otto-Apel, até mesmo a logic of science neopositivista, que alegava negar toda a metafísica, possuía seus pressupostos transcendentais, começando pelo pressuposto da validade da lógica formal sem o qual o projeto de uma tradução da experiência em termos lógicos careceria de sentido (OTTOAPEL, 1994, p. 3).

Sem que o espírito ordene o real, sem que ele possa fazer aquilo que os antigos gregos fizeram, que foi buscar explicar a diversidade e multiplicidade dos fenômenos naturais complexos e variados postulando causas únicas e simples, fazendo emergir assim uma imagem ordenada de natureza, sem que adote pressupostos básicos, a saber, que há uma configuração das coisas que responde pelo nome de ordem, que tal configuração corresponde ou à natureza do mundo ou ao modo por meio do qual o entendimento se relaciona com o mundo, não pode haver ciência. Em As relações entre a física experimental e a física matemática, Poincaré volta a reforçar a importância da lei e da harmonia como pressupostos para a pesquisa científica. O cientista tem que ordenar, não lhe basta colecionar fatos, pois o ponto vital da atividade científica é ordenar tais fatos descobrindo suas regularidades e conexões. Ignorar que o cientista busca a ordem (e a produz) significaria desconhecer por completo o verdadeiro caráter da ciência (POINCARÉ. 2008, p. 223). Um pouco mais à frente, Poincaré discorre sobre dois outros pressupostos da investigação natural: unidade e simplicidade:

Em certa medida, toda generalização pressupõe a crença na unidade e na simplicidade da natureza. [...] Logo, não temos que nos perguntar se

\footnotetext{
${ }^{5}$ Lembramos, para fazer um paralelo, que, em Vida de Laboratório Latour e Woolgar definem os fatos como enunciados tácitos cuja história foi esquecida; seus rastros foram apagados. Um enunciado de tipo 6 (que possui o maior nível de "faticidade") dizem os autores, "está tão incorporado na prática que não há mais necessidade de mencioná-lo" (p. 84). Em nossa interpretação da obra latouriana, o próprio fato de que há fatos é um pressuposto, ou, dizendo de outro modo, muitos dos fatos básicos que são pré-condições dos modos de pensar e agir dos cientistas, são pressupostos. Conforme Latour e Woolgar: "chega-se logo ao estágio em que ele [o enunciado] não é mais objeto de contestação. No centro desse movimento browniano, constituiu-se um fato" (p. 91). Pressupomos, por exemplo, que a terra orbita o sol e gira em torno de seu próprio eixo. O heliocentrismo, assim, é um fato para nós. É tão óbvio e natural, que esquecemos completamente de como ele chegou a ser um fato, por meio de quais controvérsias, estratégias, disputas, argumentos, teorias e observações, ele veio a se tornar um fato, de modo que a cada dia não precisamos, novamente, rever sua história, pois já pressupomos, já aceitamos de antemão que não se trata de um enunciado, de uma hipótese ou de um modelo, mas da própria descrição verdadeira do real. Ver: LATOUR, Bruno; WOOLGAR, Steve. Vida de Laboratório: a produção dos fatos científicos. Angela Ramalho Vianna (Trad.). Rio de Janeiro: Relume Dumará, 1997.

${ }^{6}$ Em Solipsismo metódico como pressuposto transcendental da ideia da ciência unitária, Otto-Apel, indo na contramão do que afirmei acima acerca do "não-solipsismo" como um pressuposto básico tácito, afirma que o solipsismo metódico é um pressuposto transcendental do neopositivismo: "a concepção objetivista da ciência unitária retrocede a um pressuposto que o neopositivismo compartilha estranhavelmente com a tradicional Filosofia da Ciência da Modernidade, como ponto de partida de uma analítica da linguagem: o pressuposto do solipsismo metódico. De maneira semelhante a Descartes, Locke, B. Russel e ainda Husserl, também o neopositivismo parte em última análise do pressuposto de que, em princípio, "um só" poderia conhecer algo como algo e dessa forma fazer ciência".
} 
a natureza é una, mas de que modo ela é una. [...] os que creem que as leis naturais devam ser simples continuam a ser obrigados, muitas vezes, a agir como se acreditassem nisso. Não poderiam furtar-se inteiramente a essa necessidade sem impossibilitar qualquer generalização e, por conseguinte, toda a ciência. (POINCARÉ, 2008, p. 227).

O que nos disse Poincaré até aqui senão que a investigação científica da natureza exige do pesquisador que este assuma pressupostos metafísicos e princípios axiológicos? A ciência não se faz sem crenças, pressupostos e valores. Até mesmo as atividades experimentais não são neutras, não são apenas "práticas puras" destituídas de tais elementos:

Diz-se com frequência que é preciso experimentar sem ideias preconcebidas. Isso não é possível; não apenas equivaleria a tornar estéril qualquer experimento, como veríamos que se trata de uma impossibilidade. Cada um traz em si sua concepção de mundo, da qual não pode desfazer-se com tanta facilidade. É preciso, por exemplo, servirnos da linguagem; nossa linguagem é repleta de ideias preconcebidas, e nem poderia ser de outro modo. Só que se trata de ideias preconcebidas inconscientemente, mil vezes mais perigosas que as outras. (POINCARÉ, 2008, p. 225).

Em toda atividade científica as ideias pré-concebidas desempenham relevante papel. Em nossa interpretação, Poincaré trabalha com duas classes de ideias pré-concebidas: as "perigosas" e as necessárias, ambas inevitáveis, cuja eliminação é impossível. Daí resulta que nenhuma prática científica é uma "prática pura" epistemicamente neutra, pois qualquer que seja o procedimento de pesquisa, sempre há uma base de ideias atuando, consciente ou inconscientemente. Se quisermos utilizar a palavra "teoria" em sentido bastante aberto e pouco rigoroso, apenas designando uma ideia ou conjunto de ideias, então poderemos dizer que isso significa que toda prática pressupõe uma teoria. As experimentações, deste modo, estão impregnadas de teoria.

Em nossa leitura, é isso o que diferencia ideologia e metafísica. A atividade científica sempre está eivada por uma tanto quanto por outra. A ideologia é formada por aquelas ideias inevitáveis e inconscientes, possivelmente, mas não necessariamente perigosas que o investigador carrega consigo, e das quais não consegue se despir quando, por exemplo, entra no laboratório, realiza uma observação, executa um experimento, interprata um dado experimental. A metafísica é formada por aquelas ideias que o pesquisador deve assumir conscientemente como seus pressupostos: ele não somente não tenta se despir delas, como é "obrigado" a vesti-las por onde quer que vá, como um par de lentes que ele utiliza para ver o mundo. São pressupostos como ordem, unidade e simplicidade.

Poincaré assume que a prática científica possui pressupostos metafísicos e princípios axiológicos, isto é, valores. Ilustra como determinadas "tensões constitutivas" estão presentes ao longo da história da ciência. Poincaré não está alheio ao jogo de interesses que se passa nas práticas científicas. Sabe que, por um lado, a ciência é defendida como uma busca desinteressada pela verdade, mas que essa visão não é única e não está acima de críticas, pois, por outro lado, há quem defenda que o valor da ciência pode e deve ser medido por seus resultados práticos concretos. Justamente por estar ciente de tais tensões é que se pergunta pelo 
valor da ciência, e conclui que este não pode depender do grau de utilidade prática dos resultados conquistados. O investigador deve estudar os fatos para expor as regularidades que os unificam pela lei, revelando a harmonia da natureza, e não simplesmente para desenvolver utilidades práticas. Em uma linguagem atual, o objetivo da ciência não é desenvolver tecnologia e inovação. Isso pode ser uma consequência do conhecimento gerado, e mesmo o meio para gerar novos saberes, mas não a finalidade da pesquisa científica:

Não podemos conhecer todos os fatos, e é preciso escolher aqueles que são dignos de ser conhecidos. A se acreditar em Tolstoi, os cientistas fariam a escolha ao acaso, em vez de fazê-lo - o que seria razoável - tendo em vista aplicações práticas. Os cientistas, ao contrário, creem que certos fatos são mais interessantes que outros porque completam uma harmonia inacabada, ou porque fazem prever um grande número de outros fatos. Se estão errados, se essa hierarquia dos fatos que implicitamente postulam não é mais que vá ilusão, não poderia haver ciência pela ciência, e por conseguinte não poderia haver ciência. Quanto a mim, creio que eles têm razão e, por exemplo, mostrei anteriormente qual é o alto valor dos fatos astronômicos, não porque sejam suscetíveis de aplicações práticas, mas porque são os mais instrutivos de todos. (POINCARÉ. 1995, p. 172).

Este trecho acima é muito significativo, em nossa interpretação, por diversas razões. Primeiro, porque Poincaré admite a pluralidade e a vastidão do real, uma vez em que assume que a quantidade de fatos é tamanha que não podemos conhecer a todos os tipos de fatos, logo, temos que fazer uma escolha. A realidade é vasta, o real nos ultrapassa, transcende nossa capacidade de conhecimento global e definitivo. Como essa escolha pode ser feita, e como é realmente feita? A escolha poderia obedecer três caminhos. (1) Ao acaso, conforme Tolstoi, (2) objetivando aplicações práticas (seria a escolha utilitarista), ou, (3) enfim, pela crença em uma hierarquia dos fatos, ou seja, pelo pressuposto de que há uma harmonia da natureza, e que alguns fatos podem nos levar a uma maior compreensão dessa harmonia do que outros. Os cientistas, argumenta Poincaré, optam por essa terceira via, portanto negam tanto o acaso quanto o utilitarismo. E é também nessa resposta que ele acredita. Sem esse pressuposto, que repousa, em última instância, em uma crença, diz o autor, não poderia haver ciência pela ciência.

Ora, não poderia haver ciência sem o ideal de "ciência pela ciência"? Não. Responde o matemático. Sem a ciência como fim, não haveria o que se possa chamar de ciência como um meio. A "ciência pela ciência" é o núcleo, o fundamento, do ideal de ciência. Entendemos isso de dois modos: (i) Pode haver ciência pura, ou básica, sem ciência aplicada (o que não é desejável), mas não pode haver ciência aplicada sem ciência básica. Há entre esses dois modos de pesquisa tensões, interdependências, correlações, entrelaçamentos. O quadro real é deveras complexo e muitas vezes podemos ter dificuldade para entender onde uma termina e a outra começa. Mas, ainda assim, entre ambas, parece haver uma relação de necessidade e contingência, em sentido lógico. A ciência básica é necessária em relação à ciência aplicada, pois sem pesquisa básica, o mercado de inovações tende a esgotar-se à medida que cria e recria a partir do já conhecido; (ii) A "ciência pela ciência" é o núcleo do ideal de ciência não somente pelas 
considerações acima, mas porque contém aquela base metafísico-axiológica, em suma, o "espírito" da pesquisa científica. Sem esse espírito, o que fica? Sem o ethos da "ciência pela ciência" a pesquisa se reduz a um modo de produção a partir de um conjunto de técnicas, para suprir demandas práticas da vida social e econômica e satisfazer interesses estratégicos de determinados grupos. Estamos mais que dispostos a considerar que a ciência é isso também, mas não a conceber que seja só isso.

Esse ideal de ciência pela ciência nos permite entender como, para Poincaré, a questão acerca do valor da ciência responde uma questão ainda mais ampla, "qual é o valor da civilização?". Isto é; o problema do valor da ciência é também a pergunta por sua importância cultural, pelo espaço que ela ocupa em nossa vida espiritual, pela sua posição na tradição intelectual. Perguntar pelo valor da ciência é também perguntar "o que é a civilização sem a ciência?". Se sem ciência a civilização fica mais pobre apenas materialmente, então seu valor é somente prático e utilitário, mas, se sem ciência nossa pobreza é também espiritual, se não perdemos somente máquinas e arranha-céus, indústrias e suas benesses, mas "algo a mais", se perdemos cosmovisões, se o que perdemos é o modo como compreendemos a nós mesmos e ao mundo, um jeito de pensar, de ver, de encarar as coisas, se perdemos um universo simbólico, um estilo de pensamento e um modo de ver o mundo, então perder a ciência não seria para a vida intelectual, para a cultura, um empobrecimento menor do que perder a arte, por exemplo. Perder a ciência é perder parte fundamental da cultura. É nos perder enquanto civilização.

Em suma, para Poincaré, nosso problema assume uma resposta bastante interessante. A ciência pela ciência é parte fundamental do valor da civilização:

Só pela ciência e pela arte as civilizações têm valor. Alguns espantaram-se com a fórmula "a ciência pela ciência"; e contudo ela não é menos surpreendente que "a vida pela vida", se a vida não é mais que miséria; e até mesmo do que "a felicidade pela felicidade", se não julgarmos que todos os prazeres são da mesma qualidade, se não quisermos admitir que o objetivo da civilização é o de fornecer álcool aos que gostam de beber (POINCARÉ. 1995, p. 172). [grifo nosso].

Pensar que o objetivo da ciência é fornecer máquinas aos que desejam produzir é como pensar que o objetivo da civilização é o de fornecer álcool aos que gostam de beber. Perguntar para o que serve a ciência, ou como a ciência é útil, é tão pouco razoável, ou tão non sense, quanto perguntar para o que serve a civilização, ou para o que a civilização é útil. Ora, argumentamos que a civilização "é tudo", e por isso mesmo, "não serve para nada", pois não há nada "fora" dela. A civilização não é um meio, mas o fim. Não é "por meio da" civilização que alcançamos a realização pessoal, a evolução espiritual, a felicidade, e quaisquer outras noções cuja definição rigorosa nos escapa por entre os dedos. É "na" civilização, qualquer que seja, que podemos fazê-lo. Se Poincaré está certo, e o valor da civilização emana da ciência e da arte, se uma civilização possui valor não por suas guerras e conflitos, nem pela grandiosidade e eloquência de suas maquinarias, ou pelo tamanho de seu território, mas pelo legado de suas ciências e de suas artes, quanto menor, ou mais restrito o valor da ciência e da arte, mais pobre a própria civilização. 


\section{Considerações finais}

Nosso "Fio de Ariadne" é a questão "qual é o valor da ciência?". A ciência de Poincaré possui um ethos compatível com o pressuposto de que a pesquisa natural pode se aproximar da verdade e da unidade da natureza, contemplando e se deleitando com sua beleza e harmonia. A busca da verdade enquanto valor na axiologia de Poincaré não está em desacordo com sua epistemologia convencionalista. $O$ convencionalismo não nega a "verdade", mas apresenta uma teoria da verdade distinta daquela defendida por realistas. Para Poincaré a ciência é importante tanto para a cultura quanto para a vida prática, e assim como é valiosa para nossa cosmovisão, para as respostas que damos a questões fundamentais como quem somos e qual é o nosso lugar na existência universal, também o é para a indústria e para o bem-estar humano. Deste modo, a busca pelo conhecimento puro por meio do pensamento livre e desinteressado e a condução da pesquisa pelos interesses em aplicações práticas se desenvolvem paralelamente em uma relação eivada por convergências, sobreposições e tensões. Poincaré pensa que, em grau mais elevado, a ciência pela ciência, junto com a arte, possui inestimável valor cultural e sustenta nosso ideal de civilização, e que o desenvolvimento áureo da tecnologia poderia nos libertar para uma vida mais contemplativa e espiritual.

Poincaré não negava a utilidade, mas o utilitarismo. A utilidade prática, decorrente de avanços em tecnologia e inovação, é uma consequência da pesquisa científica, mas não seu fim. O utilitarismo seria uma concepção empobrecedora das atividades humanas, que pensaria que a finalidade da ciência é servir a propósitos práticos. O cientista filósofo francês cultivava uma visão de ciência pela ciência. Não é em nome da utilidade que o cientista pesquisa a natureza, mas da beleza. A vida não valeria a pena ser vivida se a natureza não fosse bela. $O$ cientista deve buscar a verdade por que a verdade é bela. A verdade natural e a verdade moral se reforçam, pois a busca da verdade demanda valores morais elevados. Verdade, bem e beleza inspiram o ideal de ciência pela ciência. $O$ valor da ciência é existencial. Ela nos permite sondar a beleza do mundo.

\section{Referências}

BLACKBURN, Simon. Dicionário Oxford de filosofia. Tradução de Desidério Murcho et al. Consultoria da edição brasileira, Danilo Marcondes. Rio de Janeiro: Zahar, 1997.

BOHR, Niels. Física atômica e conhecimento humano. Vera Ribeiro (Trad.). Rio de Janeiro: Contraponto, 1995.

COUTO, Joaquim Miguel et al. Desemprego tecnológico: Ricardo, Marx e o caso da indústria de transformação brasileira (1990-2007). Econ. soc., Campinas, v. 20, n. 2, p. 299-327, Aug. 2011.

CUPANI, Alberto. A tecnologia como problema filosófico: três enfoques. Sci. stud., São Paulo, v. 2, n. 4, p. 493-518, Dec. 2004.

FREYRE, Gilberto. Ainda a questão da "arte pura". In: Gilberto Freyre. DINIZ, Clarissa; HEITOR, Gleyce (Orgs.). Rio de Janeiro: Funarte, 2010. (Coleção Pensamento Crítico). 
GALISON, P. Einstein's clocks, Poincaré's maps: empires of time. New York: W. W. Norton, 2004.

LATOUR, Bruno; WOOLGAR, Steve. Vida de Laboratório: a produção dos fatos científicos. Angela Ramalho Vianna (Trad.). Rio de Janeiro: Relume Dumará, 1997.

LÉVI-STRAUSS, Claude. O Pensamento selvagem. Tânia Pellegrini (Trad.). Campinas-SP: Papirus, 1989.

. Race and history. Paris: Unesco, 1952.

LLOSA, Mario Vargas. A Civilização do Espetáculo. Ivone Benedetti (Trad.). Rio de Janeiro: Objetiva, 2013.

MARX, Karl. Maquinaria e trabalho vivo - os efeitos da mecanização sobre o trabalhador in Manuscritos. Diego Grossi Pacheco (Trasc.). Disponível em: < https:// www.marxists.org/portugues/marx/1863/05/maquinaria.htm\#trl > .

OLIVEIRA, Aercio Barbosa. Originalidade e inovação na filosofia das ciências contemporânea: ainda faz sentido tratá-las como termos distintos? 2015. 158f. Dissertação (Mestrado em Filosofia) Instituto de Filosofia e Ciências Humanas, Universidade do Estado do Rio de Janeiro, Rio de Janeiro, 2015.

OTTO-APEL, Karl. Estudos de moral moderna. Benno Dischinger (trad). Petrópolis: Editora Vozes, 1994, p. 3.

PATY, M. A criação científica segundo Poincaré e Einstein. Estud. av., São Paulo, v. 15, n. 41, p. 157-192, Apr. 2001.

PAZ, M. O convencionalismo de Poincaré contextualizado. Kairós. Revista de Filosofia, v. 7, p. 151-166, 2013. Centro de Filosofia das Ciências da Universidade de Lisboa.

PHILOT, A. C. A função e natureza das convenções e hipóteses segundo o convencionalismo francês da virada do século XIX para o XX: relações entre ciência e metafísica nas obras de Henri Poincaré, Pierre Duhem e Édouard Le Roy. 2015. 62 f. Dissertação (Mestrado em Filosofia) - Instituto de Filosofia e Ciências Humanas, Universidade do Estado do Rio de Janeiro, Rio de Janeiro, 2015.

POINCARÉ, Henri. Ensaios fundamentais. Vera Ribeiro (Trad.). Rio de Janeiro: Contraponto, 2008.

- O Valor da ciência. Helena Franco Martins (Trad.). Rio de Janeiro: Contraponto, 1995.

. The Value of Science. New York: The Science Press. 1907.

PRADO JÚNIOR, Caio. Esboço dos fundamentos da teoria econômica. São Paulo: Brasiliense, 1957.

ROPS, Daniel. Para um futuro humano. In: Para Além da Ciência. Eduardo Pinheiro (Trad.) Porto: Livraria Tavares Martins, 1955.

SILVA, Vinicius Carvalho da. Os microscópios de Galison e os telescópios de Jammer: qual imagem de ciência nos interessa mais?. In: Scientiarum Historia VIII, 2015. Filosofia, Ciências e Artes: conexões interdisciplinares - (In)certezas e (In)completudes. Rio de Janeiro: UFRJ-HCTE, 2015. v. 1. p. 44. 
. Teoria Quântica, Física Nuclear e Filosofia Grega: ensaio sobre os físicos filósofos do século XX. Griot, Revista de Filosofia. Amargosa, Bahia, v. 15, n. 1, p. 233-250, junho/2017.

VIDEIRA. A Inevitabilidade da filosofia na ciência natural do século 19. Ijuí: Editora Unijuí, 2013.

. Poincaré e as hipóteses indiferentes. Revista da SBHC, n. 17, p. 3-10, 1997.

\section{Sobre o autor}

\section{Vinicius Carvalho da Silva}

Doutor e Mestre em Filosofia da Ciência e Teoria do Conhecimento pela Universidade do Estado do Rio de Janeiro com estudos pela UFRJ. Pesquisador de pós-doc pelo IMS-UERJ. Bacharel em Filosofia pela UERJ. Fez estudos de pós-graduação em História das Ciências e da Saúde na Fiocruz (COC-Fiocruz). É professor na Universidade Estadual do Tocantins. Como membro do ECTS-CNPq, é professor convidado na disciplina de Filosofia da Ciência na pós-graduação em Biofísica do Instituto de Biofísica Carlos Chagas Filho da Universidade Federal do Rio de Janeiro. Lecionou Epistemologia e História e Teoria da Ciência na Universidade Federal do Tocantins. É colaborador do Hands on Particle Physics ou "Trabalhando com o CERN" do Instituto de Física Armando Dias Tavares da UERJ. Pesquisador em Epistemologia e Filosofia da Ciência com experiência em História da Ciência.

Recebido em 13/05/2019

Aprovado em 12/09/2019

\section{Como referenciar esse artigo}

SILVA, Vinicius Carvalho da. O valor da ciência e a busca por verdade, bem e belo na filosofia de Henri Poincaré. Argumentos: Revista de Filosofia. Fortaleza, ano 11, n. 22, p. 59-71, jul.-dez. 2019. 